\title{
Septicaemia after colonoscopy in patients with cirrhosis
}

\author{
J R Thornton, M S Losowsky
}

\begin{abstract}
Two patients with ulcerative colitis and chronic active hepatitis with cirrhosis, who developed Gram negative septicaemia after colonoscopy are described. These and two similar reported cases indicate that giving prophylactic antibiotics to patients with cirrhosis undergoing colonoscopy should be considered, particularly when the cirrhosis is advanced.
\end{abstract}

Prophylactic antibiotics have been advised for patients undergoing colonoscopy who have valvular heart disease, cardiac prostheses, severe immunodepression, or hepatic cirrhosis with ascites. ${ }^{1}$ The last of these recommendations is based on a single case report in which it was not certain that colonoscopy was responsible for the infection, as hepatic angiography was performed the day before peritonitis developed. ${ }^{1}$ We were unaware of this case but our recent experience suggests that this recommendation is valid.

\section{Case reports}

\section{PATIENT I}

A 56 year old woman underwent routine colonoscopy. She had had ulcerative colitis involving the whole of her colon for 25 years. For the past seven years, the colitis had been quiescent. Ten years earlier, she had become jaundiced and a liver biopsy specimen showed chronic active hepatitis and cirrhosis. She was negative for hepatitis B markers. Nine and five months before her admission for colonoscopy, she had been admitted for treatment of ascites.

At this admission, she felt reasonably well. Her medication was prednisolone $7.5 \mathrm{mg}$ daily and spironolactone $100 \mathrm{mg}$ daily. Ascites was not evident on clinical examination. Pre-endoscopy blood tests showed: bilirubin $88 \mu \mathrm{mol} / \mathrm{l}$ (normal less than $15 \mu \mathrm{mol} / \mathrm{l}$ ), alanine aminotransferase 41 IU/l (normal less than $35 \mathrm{IU} / \mathrm{l}$ ), alkaline phosphatase $224 \mathrm{IU} / \mathrm{l}$ (normal less than $241 \mathrm{IU} / \mathrm{l}$ ), albumin $25 \mathrm{~g} / \mathrm{l}$ (normal greater than $37 \mathrm{~g} / \mathrm{l}$ ), prothrombin time 20 seconds (control 14 seconds).

After bowel preparation with three litres of Golytely, colonoscopy to the caecum was performed. She had inactive, total colitis. Four biopsy specimens were taken. The next day she developed a fever of $39 \cdot 5^{\circ} \mathrm{C}$. Two blood cultures grew Escherichia coli. Urine cultures were negative. Abdominal ultrasound showed a small liver without dilated bile ducts. There were no stones in the biliary system. Ascites was absent. She was treated with cephradine and made a good recovery.
PATIENT 2

In 1987 , a 34 year old man underwent routine colonoscopy because of his ulcerative colitis of 12 years' duration. Twenty three years earlier a liver biopsy had shown that he had chronic active hepatitis and cirrhosis. Hepatitis B markers were negative. In 1983 he developed ascites and had remained on spironolactone since then.

At the time of his colonoscopy he claimed that he felt reasonably well and was continuing to work. However, he had a moderate amount of ascites. His medication was: prednisolone $5 \mathrm{mg}$ daily, spironolactone $200 \mathrm{mg}$ daily, and sulphasalazine $1 \mathrm{~g}$ twice daily. Preoperative blood tests were: bilirubin $53 \mu \mathrm{mol} / \mathrm{l}$, alanine aminotransferase $38 \mathrm{IU} / 1$, alkaline phosphatase $206 \mathrm{IU} /$ 1, albumin $28 \mathrm{~g} / \mathrm{l}$, prothrombin time 16 seconds (control 14 seconds).

After bowel preparation with three litres of Golytely, colonoscopy to the caecum was performed. An inactive, total colitis was found. Six biopsy specimens were taken. His spironolactone dosage was doubled to $400 \mathrm{mg}$ daily.

Three daýs later, he was readmitted to hospital complaining that for the last two days he had felt unwell, had been vomiting, and had diffuse abdominal pain. On examination he had generalised abdominal tenderness. A diagnostic ascitic tap showed a very high white cell count of $1 \cdot 7 / \mu \mathrm{l}$ (88\% neutrophils). The ascitic fluid and two blood cultures subsequently grew $E$ coli. Urine culture was sterile. An abdominal ultrasound showed a small liver, enlarged spleen, and moderate ascites. The biliary tree was not dilated and no gall stones were seen. He recovered after treatment with cefuroxime and gentamicin.

Fifteen months later, he was admitted for assessment for a liver transplant as he had become increasingly tired, more jaundiced (serum bilirubin $116 \mu \mathrm{mol} / \mathrm{l}$ ), and his ascites had become resistant to diuretic treatment. Because of the considerable immunosuppressive treatment he would receive after a transplant, which might promote the development of any preexisting colonic dysplasia or neoplasia, it was decided to perform a further colonoscopy. This time the patient was given antibiotic prophylaxis with ciprofloxacin $200 \mathrm{mg}$ and metronidazole $500 \mathrm{mg}$ intravenously one hour before and eight hours afterwards. No clinical evidence of infection subsequently developed. Two days after the endoscopy, blood and ascitic cultures were sterile, and the ascitic white cell count was $0 \cdot 1 / \mu l$.

\section{Discussion}

These two patients indicate that potentially fatal infections may occur if prophylactic antibiotics 
are not used in patients with cirrhosis undergoing colonoscopy. Our first patient shows that this may happen even if ascites is absent, though this patient had had ascites previously. The second patient shows that antibiotics may be effective in preventing serious infection after colonoscopy, despite the presence of ascites and previous ascitic infection.

Bacteraemia may occasionally follow colonoscopy, the reported incidence ranges from $0-17 \% .^{2}$ Patients with liver disease are likely to be less able to clear this bacteraemia because of their compromised immune function and portal systemic shunting of blood away from hepatic Kupffer cells. ${ }^{3}$ In addition, our patients were taking small doses of predisolone, which may have further impaired their immune systems.

Whether it would be prudent to give antibiotics to all patients with cirrhosis before colonoscopy is unclear. As ulcerative colitis is associated with an increased incidence of serious liver diseases such as sclerosing cholangitis and chronic active hepatitis, ${ }^{4-6}$ this will not be an uncommon consideration. On the basis of our experience and the two other similar cases reported, ${ }^{17}$ it seems advisable at least to give antibiotics to those patients with cirrhosis who have or have had ascites, or those who are approaching or have received liver transplantation.

1 Macrae FA, Tan KG, Williams CB. Towards safer colonoscopy: a report on the complications of 5000 diagnostic or therapeutic colonoscopies. Gut 1983; 24: 376-83.

2 Meyer GW. Prophylaxis of infective endocarditis during colonoscopy: report of a survey. Gastrointest Endosc 1981; 27 : 58-9.

3 Runyon BA. Spontaneous bacterial peritonitis: an explosion of information. Hepatology 1988; 8: 171-5.

4 Olsson R, Hulthen L. Concurrence of ulcerative colitis and chronic active hepatitis. Scand $\mathcal{F}$ Gastroenterol 1975; 10: chronic.

5 Dew MJ, Thompson H, Allan RN. The spectrum of hepatic dysfunction in inflammatory bowel disease. $Q \mathcal{F} \mathrm{Med} 1979$; dysfunction $113-35$

6 Chapman RWG, Arborgh BAM, Rhodes JM et al. Primary sclerosing cholangitis: a review of its clinical features, cholangiography and hepatic histology. Gut 1980; 21: 870-7.

7 Shrake PD, Troiano F, Rex DK. Peritonitis following colonoscopy in a cirrhotic with ascites. Am $\mathcal{F}$ Gastroenterol 1989; 84: 